\title{
Relevant Aspects of Coronary Artery Disease in Candidates for Non-Cardiac Surgery
}

\author{
Gilson Cassem Ramos, TSA 1
}

\begin{abstract}
Summary: Ramos GC - Relevant Aspects of Coronary Artery Disease in Candidates for Non-Cardiac Surgery.
Background and objectives: Due to its prevalence, coronary artery disease (CAD) represents the main cause of morbidity and mortality in elective surgeries, which justifies this review, whose objective was to establish preoperative conducts based on rules and directive to minimize peri- and postoperative morbidity and mortality of patients with CAD.
\end{abstract}

Contents: General characteristics of CAD, as well as its physiopathogenic mechanisms, the main variables related to preoperative care of patients with $C A D$, and the conducts for patients with greater surgical risk are presented.

Conclusions: Patients with CAD who are candidates for non-cardiac surgeries should be evaluated judiciously. Those identified as being at high risk can benefit from preoperative myocardial ischemia-provoking tests, as well as from invasive coronary interventions preceding elective surgeries. In selected patients, one should consider the use of beta-blockers and statins.

Keywords: PREOPERATIVE EVALUATION; RISK FACTORS; SURGERY: Non-cardiac.

[Rev Bras Anestesiol 2010;60(6): 659-665] @Elsevier Editora Ltda.

\section{INTRODUCTION}

Cardiovascular diseases follow the aging population and represent one of the main comorbidities in patients evaluated for non-cardiac surgeries. Coronary artery disease (CAD) is one of them. Atherosclerotic cardiovascular diseases represent the main cause of death and disability in Brazil and in the world, and it is mainly attributed to CAD. According to the DATASUS (www.datasus.gov.br), approximately 140 thousand deaths/year occur in Brazil due to CAD. This means 250 thousand myocardial infarctions/year. When comparing to the data of other countries, in Brazil the number of patients with angina is, at least, 1.5 million, with approximately 50 thousand new cases/year ${ }^{1}$. It has been estimated that approximately $12 \%$ of patients who will undergo non-cardiac surgery have or are at risk for coronary artery disease ${ }^{2,3}$. In this context, the clinician, surgeon, and anesthesiologist are frequently faced with surgical patients with CAD and for this reason some of the aspects related to the management of those patients can be fundamental for the success of the surgery with a reduction in morbidity and mortality.

Received from the Cardiology Department of Hospital Samaritano de Goiânia/GO and Check up Cardiológico Samaritano Co., Goiânia/GO.

1. Cardiologist; Hypertension Specialista at SBH; Head of Check up Cardiológico Samaritano Co. and Cardiology Department of Hospital Samaritano de Goiânia/GO, Brazil.

Submitted on May, 31, 2010.

Approved on June 28, 2010.

Correspondence to:

Dr. Gilson Cassem Ramos

Rua 8, N. 74, Ap. 402, S.

Oeste

74115-100 - Coiânia, GO

E-mail: gilson.ramos@terra.com.br

\section{General and perioperative considerations}

In clinical practice, in $90 \%$ of the cases the physiopathogenic substrate of CAD is related to arterial obstruction by atherosclerotic plaques. Concerning perioperative myocardial infarction this mechanism is responsible for approximately $50 \%$ of the cases. The other half is related to situations in which $\mathrm{O}_{2}$ delivery is not enough to meet myocardial demand ${ }^{4}$. Thus, in patients with CAD the surgical-anesthetic stress and other perioperative factors (tachycardia, hypo- and hypertension, hypoxemia, and etc.) that interfere with the cardiorespiratory response can break the balance between $\mathrm{O}_{2}$ delivery and demand, as well as cause rupture of the vulnerable coronary plaque and, consequently, myocardial ischemia. Infarction without elevation of the ST segment is more common during this period, and elevation of the ST segment and the presence of $Q$ wave are rare ${ }^{5}$.

Coronary artery disease is classified into two clinical types: stable and unstable angina. Angina that maintains its characteristics without alterations for several weeks without worsening is the clinical characteristic of stable angina. On the other hand, unstable angina has three presentations, summarized in Chart $I^{6}$. Due to its high prevalence, CAD constitutes the main cause of morbidity and mortality in elective surgeries ${ }^{7}$. In patients over 40 years of age with CAD, the incidence of myocardial infarction and cardiovascular death can be close to $7 \%$ and $3 \%$, respectively ${ }^{8}$. In those cases, it is necessary to determine their functional capability (Chart II) ${ }^{9,10}$ before elective procedures. High-risk patients are not capable of meeting four metabolic equivalents (METs). One metabolic equivalent is equal to the consumption of $3.5 \mathrm{~mL} \cdot \mathrm{kg}^{-1} \cdot \mathrm{min}^{-1}$ of $\mathrm{O}_{2}$, which corresponds to a calm individual at rest.

Preoperative planning of those patients is based on the natural history of their cardiac disease and in the risk of the sche- 
duled surgery (Chart III) ${ }^{11}$. Regarding to the natural history, the following variables should be characterized:

a) Classify angina as stable or unstable.

b) Whether the disease is evolutive or not.

c) Type of treatment instituted.

d) Functional capacity of the patient (ischemic threshold).

Thus, the following patients could benefit from preoperative provocative testing:

a) Patients with CAD schedule to undergo high or intermediate risk surgeries or vascular surgeries;

b) Patients with CAD and diabetes mellitus, or low functional capacity, or scheduled to undergo high or intermediate risk surgeries or vascular surgery;

c) Patients with low functional capacity who require vascular surgery and who present at least three additional risk factors (Chart IV) ${ }^{13}$.
When the patient has already undergone coronary angiography in some situations such as patients with over $75 \%$ obstruction of the left coronary artery; CAD affecting two or more arteries with ventricular dysfunction; or critical stenosis of the anterior descending artery with ischemic provocative test, myocardial revascularization surgery should be done prior to the non-cardiac elective surgery. Several indications for percutaneous coronary interventions $(\mathrm{PCl})$ exist ${ }^{14}$ that are beyond the scope of the present article. However, a few situations apply to patients who underwent $\mathrm{PCl}$ with implantation of a coronary stent scheduled for elective surgeries. The type of stent is the main variable to be considered: non-pharmacologic or pharmacologic (drug-eluted). The benefits of the treatment with non-pharmacologic stents were important, but with limitations in some subgroups, among them are diabetic patients with long lesions (> $20 \mathrm{~mm}$ ) and small diameter vessels $(<3 \mathrm{~mm})$ in whom restenosis is significant in the first six months after the procedure, which can be seen in 15 to $45 \%$ of the cases ${ }^{15}$. The initial objective of pharmacologic endo-

Chart I - Clinical Presentations of Unstable Angina 6

\begin{tabular}{ll}
\hline Presentation & Characteristics \\
\hline Angina at rest & $>20$ minutes for approximately one week \\
New onset angina & Onset two months ago and, at least, CCS Class III* \\
Accelerated, increasing, or progressive angina & Angina previously diagnosed, which is more severe, more frequent, and with greater duration \\
\hline $\begin{array}{l}\text { CCS: Canadian Cardiovascular Society. } \\
\text { *Important limitation, pain when walking less than two blocks or when going upstairs in normal situation and speed. }\end{array}$
\end{tabular}

Chart II - Metabolic Equivalent (MET) Classification 9,10

Metabolic equivalent Type of activity

Excellent (> 10 METs) Practices sports, such as swimming, tennis, basketball, soccer

Good (7-10 METs) Moderate recreational activities, such as bowling and dancing, and heavy housework, such as raising furniture

Moderate (4-7 METs) Running a short distance, going upstairs or climbing a hill, walking at speeds of 4 Mph, and sexual activity

Bad (<4 METs) Limited to a few housework activities, short walks with speed of up to $3 \mathrm{Mph}$

Chart III - Classification of Cardiovascular Risk According to the Type of Surgery ${ }^{11}$

\begin{tabular}{lll}
\hline High risk $(>5 \%)^{*}$ & Intermediate $(1 \% \text { a } 5 \%)^{* \star}$ & Low risk $(<1 \%){ }^{\star \star \star}$ \\
\hline Emergency surgeries & Carotid endarterectomy & Endoscopies \\
\hline Aortic and peripheral revascularization surgeries & Head and neck surgeries & Superficial procedures \\
\hline Prolonged procedures & Intrathoracic and intraperitoneal surgeries & Cataract surgery \\
\hline Procedures with large blood loss & Orthopedic and prostate surgeries & Breast surgeries \\
\hline
\end{tabular}

${ }^{*}$ More than $5 \%$ risk of cardiovascular events.

${ }^{* *}$ Between 1 and $5 \%$ risk of cardiovascular events.

${ }^{\star \star *}$ Less than $1 \%$ risk of cardiovascular events.

Chart IV - Risk Factors for Myocardial Ischemia ${ }^{13}$

\begin{tabular}{|c|c|}
\hline Morbidities & History \\
\hline Coronary artery disease & $\begin{array}{l}\text { Myocardial infarction, use of nitrates, typical chest pain, inactive region ( } Q \text { wave) on ECG, positive provocative test, } \\
\text { and etc. }\end{array}$ \\
\hline Heart failure & Pulmonary edema, third heart sound on auscultation, clinical or radiological signs of pulmonary congestion \\
\hline Cerebrovascular disease & Stroke or transient ischemic attack \\
\hline Diabetes mellitus & Diagnosis of diabetes mellitus \\
\hline Renal failure & Elevated creatinine \\
\hline
\end{tabular}


prosthesis was to reduce excessive myointimal hyperplasia, the main culprit in coronary restenosis ${ }^{16}$. Thus, they reduce cellular division at the site of the implant (target-lesion) promoting lower clinical and angiographic restenosis rates ${ }^{17}$, being especially indicated in diabetics. If on the one hand the risk of intrastent restenosis is significantly lower with drug-eluted stents, on the other hand the risk of thrombosis, especially late ( $>30$ days) and very late ( $>1$ year) thrombosis, although rare $(<1)^{18}$ is greater with those devices and are related to the lower rate of endothelization. Thus, the FDA (Food and Drug Administration) ${ }^{19}$ and the directives of the European Society of Cardiology ${ }^{20}$ recommend, formal and indiscriminately, 12 months of antiplatelet therapy combined with aspirin and clopidogrel, especially the latter. Approximately 5\% of the patients undergoing $\mathrm{PCl}$ will need non-cardiac surgery in the first year after the percutaneous intervention. The surgery itself increases pro-thrombotic factors, increasing the risk of stent thrombosis. Therefore, a conflict is created between the continuity of the antiplatelet treatment in the perioperative period with inherent elevation of the risk of hemorrhage, or its discontinuation with the consequent overexposure to the risk of coronary artery thrombosis ${ }^{21,22}$. Thus, those patients are exposed to a higher risk of complications. They can have a morbidity and mortality rate five to ten times greater than those undergoing the same surgeries who are on optimized antiplatelet therapy or who have reached the necessary time for re-endothelization after implantation of stents, and they might achieve a perioperative mortality rate of $30 \%$ to $86 \%{ }^{23,24}$. Therefore, the following recommendations should guide the management of patients with CAD, who previously underwent $\mathrm{PCl}$, in elective surgeries ${ }^{12}$ :

a) In patients with non-pharmacologic stents, the procedure should be postponed for four to six weeks and they should be operated while on acetylsalicylic acid, and clopidogrel should be discontinued for at least five days prior to the procedure. b) In patients with pharmacologic stents, the surgery should be postponed for one year and, after this period the patient should be on acetylsalicylic acid for the surgery.

Transfusion of fresh platelets can, at times, be the only way of reestablishing blood coagulation in patients on antiplatelet therapy who need emergency surgery. Six to eight hours after the last dose of clopidogrel, transfused platelets will not be significantly affected by the drug 22 .

Some beta blockers, especially metoprolol, are administered preoperatively in patients with CAD as cardioprotective agents. Those drugs really reduce coronary ischemic events, but its use has been associated with higher perioperative mortality rate due to sepsis and strokes ${ }^{25}$, and therefore they should not be indiscriminately used in those patients. They should be continued in those patients with CAD who were already using them.

The use of statins has been associated with several clinical benefits. They are hypolipidemic agents that improve endothelial function, stabilize atherosclerotic plaques, and reduce vascular inflammation. However, some variables such as the ideal time to begin their use are unknown. Thus, only one Class I recommendation exists for their use, i.e., in those patients who were already taking them prior the surgery. Brazilian directives recommend their use in vascular surgeries 26 .

Patients with CAD who are candidates for non-cardiac surgeries should be evaluated and clinically compensated before any elective surgical procedure. Those patients identified as having a high risk may benefit from preoperative myocardial ischemia-provoking tests, as well as from invasive coronary interventions before elective surgeries. Beta blockers should not be used indiscriminately in those patients. Basic clinical therapeutic actualization of those patients should be known to the entire surgical team whose conducts as a group of clinician, anesthesiologist, and surgeon are decisive for the success of the procedure. 


\section{REFERÊNCIAS / REFERENCES}

01. Ferreira JFM, Timerman A - Diagnóstico e estratificação de risco na sala de emergência. Rev Soc Cardiol Est São Paulo, 2007;3:243-56.

02. Mangano DT - Perioperative cardiac morbidity Anesthesiology, 1990;72: 153-184.

03. Mangano DT, Wong MG, London MJ et al. - Perioperative myocardial ischemia in patients undergoing noncardiac surgery. II. Incidence and severity during the first week after surgery. J Am Coll Cardiol, 1991;17:851-857.

04. Poldermans D, Bax JJ, Schouten O et al. - Should major vascular surgery be delayed because of preoperative cardiac testing in intermediate-risk patients receiving beta-blocker therapy with tight heart rate control? J Am Coll Cardiol, 2006; 48:964-969.

05. Landesberg G, Mosseri M, Shatz V et al. - Cardiac troponin after major vascular surgery: the role of perioperative ischemia, preoperative thallium scanning, and coronary revascularization. J Am Coll Cardiol, 2004; 44:569-575.

06. Gibbons RJ, Abrams J, Chatterjee K et al. - ACC/AHA 2002 guideline update for the management of patients with chronic stable angina-summary article: a report of the American College of Cardiology/ American Heart Association Task Force on practice guidelines (Committee on the Management of Patients with Chronic Stable Angina). J Am Coll Cardiol, 2003; 41:159-168.

07 Hernandez AF, Newby LK, OConnor CM - Preoperative evaluation for major noncardiac surgery: focusing on heart failure. Arch Intern Med, 2004; 164:1729-1736.

08. Mangano DT, Goldman L - Preoperative assessment of patients with known or suspected coronary disease. N Engl J Med, 1995; 333:17501756. 
09. Goldman L, Hashimoto B, Cook EF et al. - Comparative reproducibility and validity of systems for assessing cardiovascular functional class: advantages of a new specific activity scale. Circulation, 1981;64:1227-1234.

10. Batlouni M - O Sistema Cardiovascular em Situações Especiais, em: Nobre F, Serrano CV Jr - Tratado de Cardiologia SOCESP. $1^{\text {a }}$ Ed, São Paulo, Manole, 2005; 1506-1519.

11. Eagle KA - Surgical patients with heart disease: summary of the ACC/ AHA guidelines. Am Fam Physician, 1997;56: 811-818.

12. Fleisher LA, Beckman JA, Brown KA et al. - ACC/AHA 2007 guidelines on perioperative cardiovascular evaluation and care for noncardiac surgery: a report of the American College of Cardiology/American Heart Association Task Force on Practice Guidelines (Writing Committee to Revise the 2002 Guidelines on Perioperative Cardiovascular Evaluation for Noncardiac Surgery) developed in collaboration with the American Society of Echocardiography, American Society of Nuclear Cardiology, Heart Rhythm Society, Society of Cardiovascular Anesthesiologists, Society for Cardiovascular Angiography and Interventions, Society for Vascular Medicine and Biology, and Society for Vascular Surgery. J Am Coll Cardiol, 2007; 50: e159-e241.

13. Auerbach $A$, Goldman $L-$ Assessing and reducing the cardiac risk of noncardiac surgery. Circulation, 2006;113:1361-1376.

14. Mattos LA, Lemos Neto PA, Rassi A Jr et al. - Diretrizes da Sociedade Brasileira de Cardiologia - Intervenção Coronária Percutânea e Métodos Adjuntos Diagnósticos em Cardiologia Intervencionista (II Edição - 2008). Arq Bras Cardiol, 2008;91:1-58.

15. Hoffmann R, Mintz GS, Dussaillant GR et al. - Patterns and mechanisms of in-stent restenosis. A serial intravascular ultrasound study. Circulation, 1996;94:1247-1254.

16. Sousa JE, Costa MA, Abizaid A et al. - Lack of neointimal proliferation after implantation of sirolimus-coated stents in human coronary arteries: a quantitative coronary angiography and three-dimensional intravascular ultrasound study. Circulation, 2001;103:192-195.

17. Sousa JE, Costa MA, Abizaid A et al. - Sirolimus-eluting stent for the treatment of in-stent restenosis: a quantitative coronary angiography and three-dimensional intravascular ultrasound study. Circulation, 2003;107:24-27.

18. Stettler C, Wandel S, Allemann S et al. - Outcomes associated with drug-eluting and bare-metal stents: a collaborative network metaanalysis. Lancet, 2007;370:937-948.

19. Laskey WK, Yancy CW, Maisel WH - Thrombosis in coronary drugeluting stents: report from the meeting of the Circulatory System Medical Devices Advisory Panel of the Food and Drug Administration Center for Devices and Radiologic Health, December 7-8, 2006. Circulation, 2007;115:2352-2357.

20. Silber S, Albertsson P, Avilés FF et al. - Guidelines for percutaneous coronary interventions. The Task Force for Percutaneous Coronary Interventions of the European Society of Cardiology. Eur Heart J, 2005;26:804-847.

21. King SB 3rd, Smith SC Jr, Hirshfeld JW Jr et al. - 2007 Focused Update of the ACC/AHA/SCAI 2005 Guideline Update for Percutaneous Coronary Intervention: a report of the American College of Cardiology/American Heart Association Task Force on Practice Guidelines:
2007 Writing Group to Review New Evidence and Update the ACC/ AHA/SCAI 2005 Guideline Update for Percutaneous Coronary Intervention, Writing on Behalf of the 2005 Writing Committee. Circulation, 2008;117:261-295.

22. Fleisher LA, Beckman JA, Brown KA et al. - ACC/AHA 2007 Guidelines on Perioperative Cardiovascular Evaluation and Care for Noncardiac Surgery: Executive Summary: A Report of the American College of Cardiology/American Heart Association Task Force on Practice Guidelines (Writing Committee to Revise the 2002 Guidelines on Perioperative Cardiovascular Evaluation for Noncardiac Surgery) Developed in Collaboration With the American Society of Echocardiography, American Society of Nuclear Cardiology, Heart Rhythm Society, Society of Cardiovascular Anesthesiologists, Society for Cardiovascular Angiography and Interventions, Society for Vascular Medicine and Biology, and Society for Vascular Surgery. J Am Coll Cardiol, 2007;50:1707-1732.

23. Bavry AA, Lincoff AM - Is clopidogrel cardiovascular medicine's double-edged sword? Circulation, 2006;113:1638-1640.

24. O'Neill WW - Risk of bleeding after elective percutaneous coronary intervention. N Engl J Med, 2006;355:1058-1060.

25. Devereaux PJ, Yang H, Yusuf $S$ et al. - Effects of extended-release metoprolol succinate in patients undergoing non-cardiac surgery (POISE trial): a randomised controlled trial. Lancet, 2008;371:1839-1847.]

26. Caramelli B, Pinho C, Calderano D et al. - I Diretriz de Avaliação Pré-operatória. Arq Bras Cardiol, 2007; 88: e139-e178.

Resumen: Ramos GC, Gilson Cassem Ramos - Aspectos Relevantes de la Enfermedad Arterial Coronaria en Candidatos a la Cirugía no Cardiaca.

Justificativa y objetivos: Debido a su prevalencia, la enfermedad arterial coronaria (DAC), constituye la principal causa de morbimortalidad en las cirugías por elección, lo que justifica la presente revisión y cuyo objetivo fue principalmente, establecer conductas preoperatorias con base en normas y directrices para minimizar la morbimortalidad peri y postoperatoria de los portadores de DAC.

Contenido: Se presentan características generales de la DAC, como también sus mecanismos fisiopatogénicos, las principales variables relacionadas con la preparación del preoperatorio de pacientes con DAC, como también conductas frente a los enfermos de mayor riesgo quirúrgico.

Conclusiones: Los portadores de DAC candidatos a la cirugía no cardiaca deben ser rigurosamente evaluados. Los identificados como de alto riesgo pueden beneficiarse con los test preoperatorios provocativos de isquemia miocárdica, y de intervenciones coronarias invasivas, precediendo a las operaciones quirúrgicas electivas. En los pacientes seleccionados, debemos considerar el uso de betabloqueantes y de estatinas. 